\title{
Integrated Renewable Energy System for Stand-Alone Operations with Optimal Load Dispatch Strategy
}

\author{
Dr. Abul Bashar, \\ Department of Computer Engineering, \\ Prince Mohammad Bin Fahd University, \\ Kingdom of Saudi Arabia. \\ Email: $\underline{\text { abashar@pmu.edu.sa }}$
}

\section{Dr. S. Smys,}

Professor,

Department of Computer Science and Engineering,

RVS Technical Campus,

Coimbatore, India.

Email: smys375@gmail.com

\begin{abstract}
The hybrid system configuration is used for meeting the thermal and electrical load demands of an off-grid network simultaneously with the model proposed in this paper. Li-ion battery, Micro Gas Turbine (MGT), wind turbine and solar photovoltaic configurations are analyzed. Hybrid Optimization of Multiple Electric Renewables (HOMER) software is used for estimating utilization of various strategies for power management, recovered waste heat and excess energy in the model. The heating demand is met and examined by the thermal load controller with and without the options of waste heat recovery. The hybrid system hardware components are sized, compared and analyzed based on cyclic charging (CC) and load following (LF) dispatch strategies. Various electrical to thermal load ratio are considered for examining the system performance. Various uncertainties and their effects are reported on comparison of grid-connected and stand-alone options. The hardware components are reduced in size thereby appreciable cost benefits are observed in the results. In the optimized hybrid system, the renewable energy fraction is increased causing high renewable penetrations and the $\mathrm{CO}_{2}$ emission is reduced by a large value. For all the configurations analyzed, several environmental and cost benefits are offered by the $\mathrm{CC}$ strategy.
\end{abstract}

Keywords: Load following, $\mathrm{CO}_{2}$ emission, Energy cost, Cyclic charging, Heat management 
Journal of Electronics and Informatics (2021)

Vol.03/ No.02

Pages: $89-98$

https://www.irojournals.com/iroei/

DOI: https://doi.org/10.36548/jei.2021.2.002

\section{Introduction}

The quality of life of people are improved by the society's sustainable progress for which there are several indispensable prerequisites, of which, energy supply is a prominent one [1]. The global urbanization and growing population has led to a significant rise in hybridized energy systems and optimized sustainable energy source utilization in this context [2]. There has been a rapid increase in the energy requirement on annual basis on the global level according to survey reports. The emission of Greenhouse Gas (GHG) into the atmosphere caused by conventional sources has also increased to a large extent over the years [3]. It is essential to hybridize multiple energy sources or include auxiliary storage devices while using renewable energy sources and ensuring $100 \%$ energy supply. This is due to the intermittent nature of availability of these renewable energy sources that depend largely on the surrounding environmental conditions.

Hybrid Optimization of Multiple Electric Renewables (HOMER) software is seldom used for analysis of battery, Micro Gas Turbine (MGT), wind and PV based hybrid systems with respect to heat recovery and electric boiler based excess energy utilization [4]. It is essential to recover the wasted electric and heat energy in these hybrid systems. This paper presents an optimized model in which the wasted electric and heat energy are recovered in hybrid systems while reducing the emission and cost. The presented model satisfies the heating demand while considering the recovery option in electric boiler by excess energy utilization [5]. The thermal and electrical load requirements are met simultaneously using this stand-alone hybrid model. Various environmental and techno-economic indicators are considered while comparing various hybrid models for performing optimal system sizing. The model's hardware components are sized while comparing the cyclic charging (CC) and load following (LF) dispatch strategies [6]. The electric boiler is used for satisfying the thermal and electrical load while recovered heat and electric boiler may be used for the thermal and electrical loads. The electrical load may be satisfied by the proposed integrated model while examining the electric load ratio and different thermal performances of the system [7]. The grid connected system with standalone power sources are also compared and analyzed. The load profiles based on the meteorological resource information and effects of various uncertainties are monitored. 
Journal of Electronics and Informatics (2021)

Vol.03/ No.02

Pages: $89-98$

https://www.irojournals.com/iroei/

DOI: https://doi.org/10.36548/jei.2021.2.002

\section{Literature Survey}

Grid/Battery/FC/PV, concentrated Grid/ Organic Rankine Cycle (ORC)/Biomass/ solar power, solar/FC/PV collector and several other system configurations are used for studying the thermal and electrical loads in various existing literature [8]. Neither hybridized battery/ Micro Gas Turbine (MGT)/wind/PV based or stand-alone energy systems may be used. It is unlikely to find stand-alone systems with excess energy generation and utilization in the existing literature. Battery/diesel/PV and standalone PV/MGT/battery systems meet the cooling, heating and electric loads as well as the thermal and highly dynamic electric nodes while optimized using genetic algorithm [9]. The thermal demands are however not met by the excess energy despite the optimization of these hybridized stand-alone systems [10]. The excess energy utilization is optimized with HOMER in few available literatures. The hydrogen, heating and electric demand are met by electrolyser/battery/diesel/wind/PV options based on their techno-economic feasibility [11]. The component sizes are maintained while attaining a reduction in the system's environmental emissions, renewable fraction, COE and fuel consumption as per the reports. Various dispatch strategies are examined while the diesel engine based waste is recovered.

The power supply for an independent building using battery/fuel cell/PV based grid-dependent options are studied [12]. HOMER software tool is used for comparison and optimization of the model while obtaining an optimal NPC and lowest COE value with heat recovery option. The electrical water heating system meets the thermal load while recovering the waste heat from the fuel cell in the system [13]. When compared to a diesel/wind option, the battery/diesel/wind system, reduced a significant amount of excess energy when integrated with a battery storage [14]. However, around 10\% excess energy is produced when a battery storage based hybridized system is used. In grid-connected systems, with low COE and hybridization of battery/diesel/PV, the excess energy may be sold to the national grid to generate an additional revenue [7]. In stand-alone or grid-independent system, this facility is not available. Thus, thermal energy may be generated by the excess energy while minimizing the environmental emissions, cost as well as the system performance in stand-alone and independent systems. HOMER tool is used for comparing the COE with GA-PSO based battery/wind/PV based 
system. HES optimization is performed with HOMER to obtain comparable COE while implementing PSO. In case of stand-alone applications, their feasibility is analyzed using the HOMER platform and its appropriateness is demonstrated [12]. The ability to quickly arrive at an optimal solution and simplicity are the reasons HOMER tool is best suited for these applications. However, other performance indicators, various uncertainties, different strategies and objective functions may be investigated thoroughly while using the standard HOMER application [15].

\section{Proposed Work}

A battery, MGT, wind and PV integrated off-grid system architecture is represented in figure 1. The AC bus is connected to the electric load, wind turbine and MGT while the DC bus is linked to the PV module. A bi-directional inverter is used for connecting both the buses. The excess energy generated by the renewable sources are used for powering an electric boiler which acts as a thermal load controller. The thermal boiler and the recovered waste heat are used for supporting the thermal load additionally. The environmental emissions are reduced while increasing the system performance by effective use of dump energy by the integration of waste heat recovery units and the thermal load controller. The thermal load controller can be incorporated for enhancing the fraction of renewable energy. 


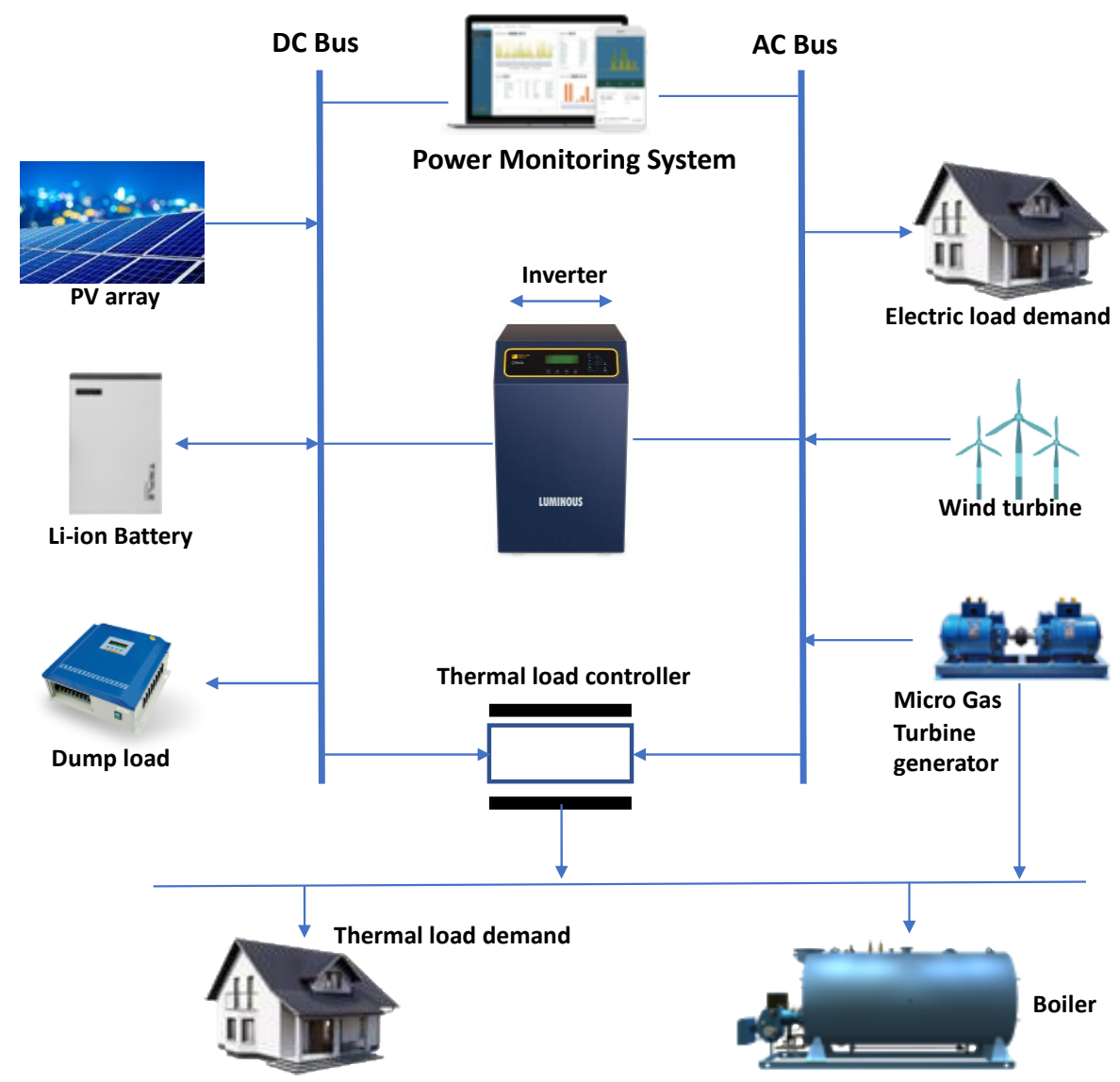

Fig. 1. Proposed integrated energy system - schematic model

The thermal and electrical load requirements are satisfied by using various system hardware components while performing optimization of software using HOMER tool. The hardware components and their techno-economic details, thermal and electrical load profile, ambient temperature, wind velocity, solar radiation and other climatic conditions are some of the input parameters included in the optimization model. The dynamic thermal and electric load requirements are met by optimization initiated based on the simulation and hourly data profiles. $\mathrm{CC}$ and LF switching algorithms or dispatch strategies are compared. The system performance variations based on the availability or unavailability of recovered waste heat and its effects are examined via optimization and simulation. The techno-economic performance variations due to the inclusion of thermal load controller in the system is also discussed. The economic, technical and hardware details, load controller, project lifetime and temporal resolution are considered as constraints in the optimization scheme. In stand-alone hybrid system, the reliable 
Journal of Electronics and Informatics (2021)

Vol.03/ No.02

Pages: $89-98$

https://www.irojournals.com/iroei/

DOI: https://doi.org/10.36548/jei.2021.2.002

power is met by the system components using HOMER while not considering the reliability indices.

\section{Results and Discussion}

HOMER optimization tool is used for determining the thermal and electrical loads simultaneously while meeting the requirements by optimal sizing of battery, MGT, wind and PV based integrated model. The addition of heat recovery unit and thermal load controller for examining the effects with main electric load is performed by adding an equivalent electric and thermal load. The thermal and total load as well as the electric load are accumulated for the purpose of analysis. When compared to the LF strategy, CC offers considerably lesser NPC an COE for battery, MSG and wind based system. The lower MGT and wind turbine capacity is also a reason for this reduction. Lesser excess energy is generated as a large battery capacity is provided since the battery is used when the load demand is not met by the MGT and wind sources. Figure 2 provides the cost summary of the proposed integrated power system.

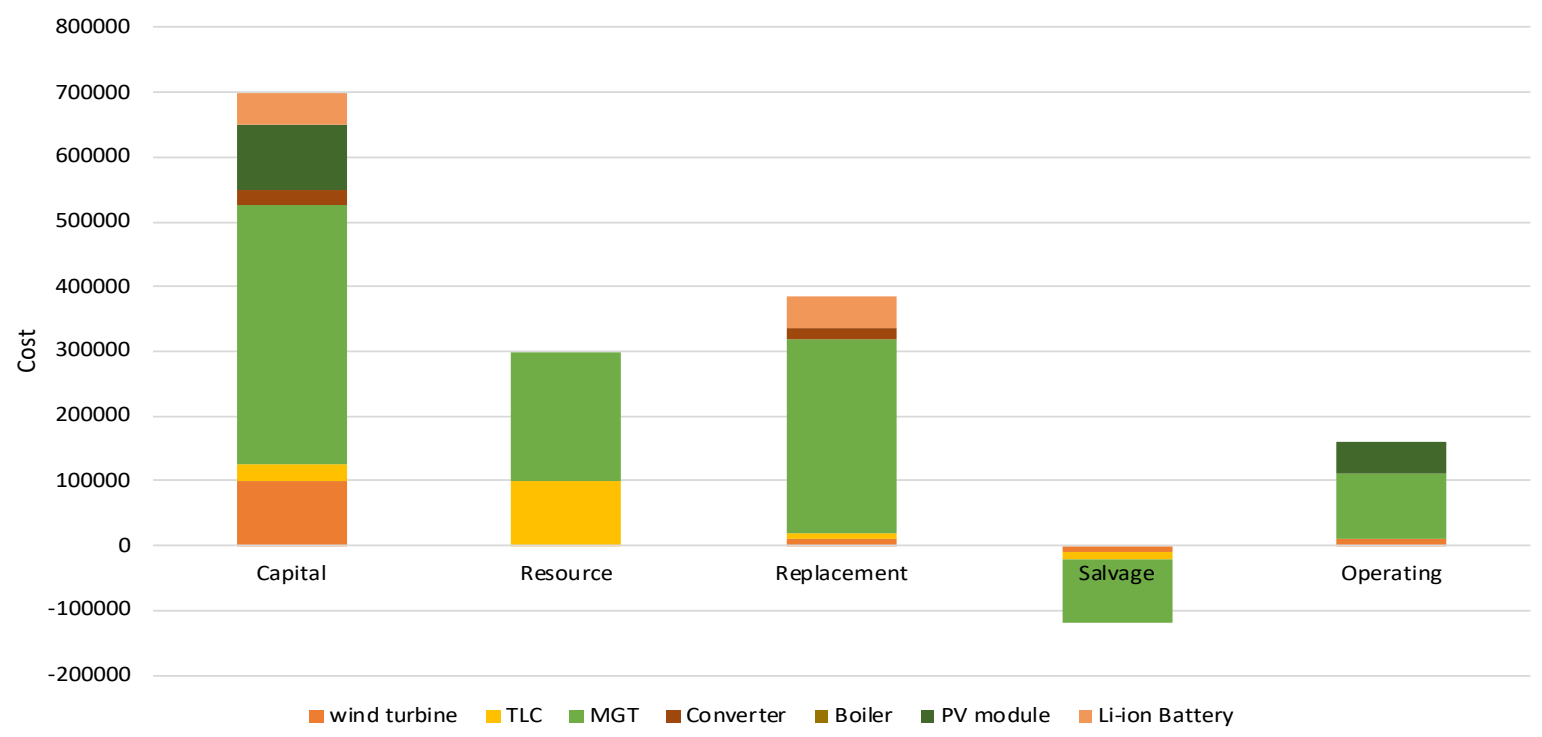

Fig. 2. Cost summary of the proposed system 
Journal of Electronics and Informatics (2021)

Vol.03/ No.02

Pages: $89-98$

https://www.irojournals.com/iroei/

DOI: https://doi.org/10.36548/jei.2021.2.002

The fuel and other resource cost, replacement, operating and capital costs are lesser when lesser number of energy sources are considered. Higher fuel cost, replacement and operating cost is essential for MGT. In CC strategy, the battery cost is high for Li-ion when compared to LF whereas, it is reversed when the PV module cost is considered. LF provides a higher thermal load to the controller than CC due to the generation of excess heat. The MGT based waste heat may be recovered for satisfying the thermal load substantially while performing heat recovery in the integrated system. This share of thermal energy is estimated over a duration of one year to estimate its performance in an experimental setup. The obtained values are represented graphically in figure 3. It is evident that during winter, the excess as well as renewable energy generation factors are considerably low. Irrespective of the strategy used, a gas-powered boiler is essential to meet the thermal demand in such scenario.

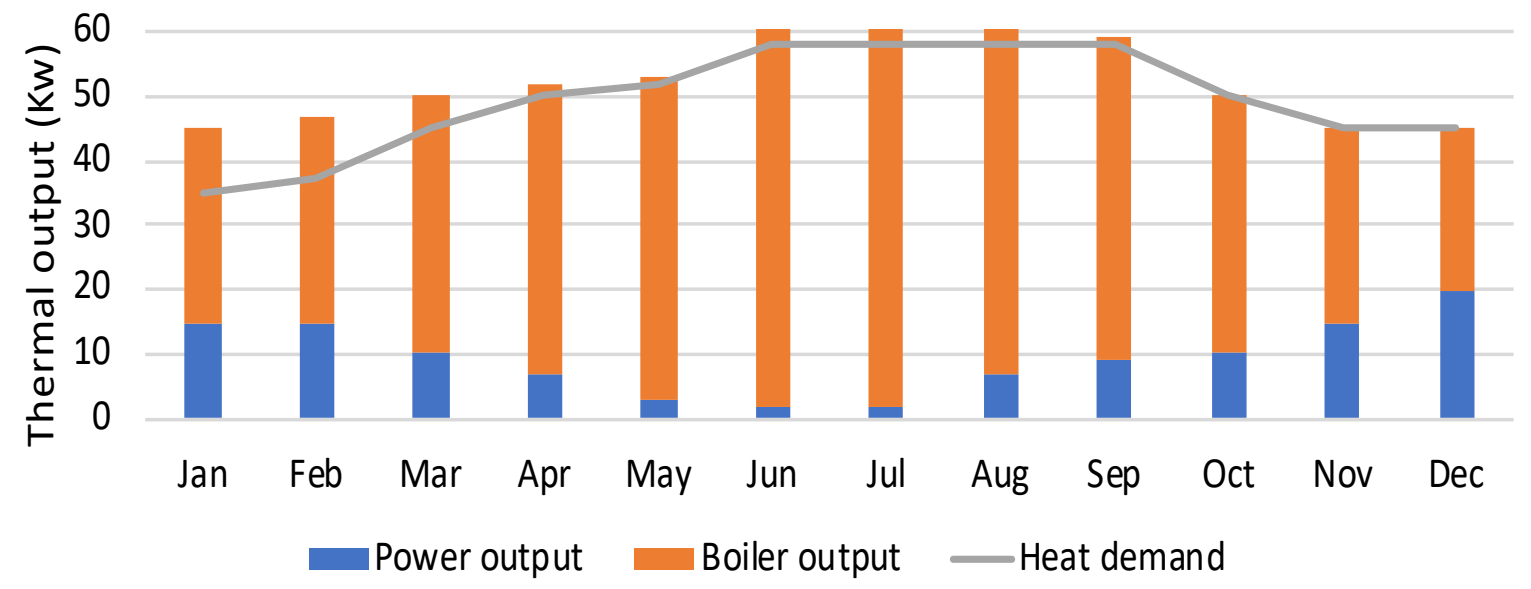

Fig. 3. Thermal energy share of the proposed model

The battery, MGT, wind and PV based integrated stand-alone system can simultaneously meet the thermal and electrical load requirements. When compared to the waste heat recovering CHP system, the environmental and cost benefits offered by the proposed system is significantly higher. In the CCHP mode, the cooling, heating and electrical loads may be satisfied by the integration of absorption or electric chillers to enhance the proposed integrated model benefits. We further examine the electrical and thermal load demand impacts. The energy cost and total net present cost is slightly affected by this ratio. Under multiple strategies, the emission of $\mathrm{CO}_{2}$ 
Journal of Electronics and Informatics (2021)

Vol.03/ No.02

Pages: $89-98$

https://www.irojournals.com/iroei/

DOI: https://doi.org/10.36548/jei.2021.2.002

is tested for environmental analysis with respect to the proposed model. Thermal and electrical loads are considered simultaneously as well as independently for the purpose of analysis. Heat recovery option and thermal load controller for satisfying the thermal and electrical loads are designed in the system to achieve significant reduction in the emission of $\mathrm{CO}_{2}$. While operating under CC strategy, the thermal and electrical loads are met using the integrated model while reducing the environmental emission by over $40 \%$ while satisfying the electric demands under similar operating conditions. However, while meeting the thermal loads by recovering waste heat, only $30 \%$ of emission can be reduced. Low cost injection is essential to achieve low fuel consumption throughout the system lifespan. In an off-grid network, the thermal demand is met by the MGT while recovering the waste heat and utilizing excess energy in the sustainable integrated energy system. Figure 4 provides the time series information of the proposed model.

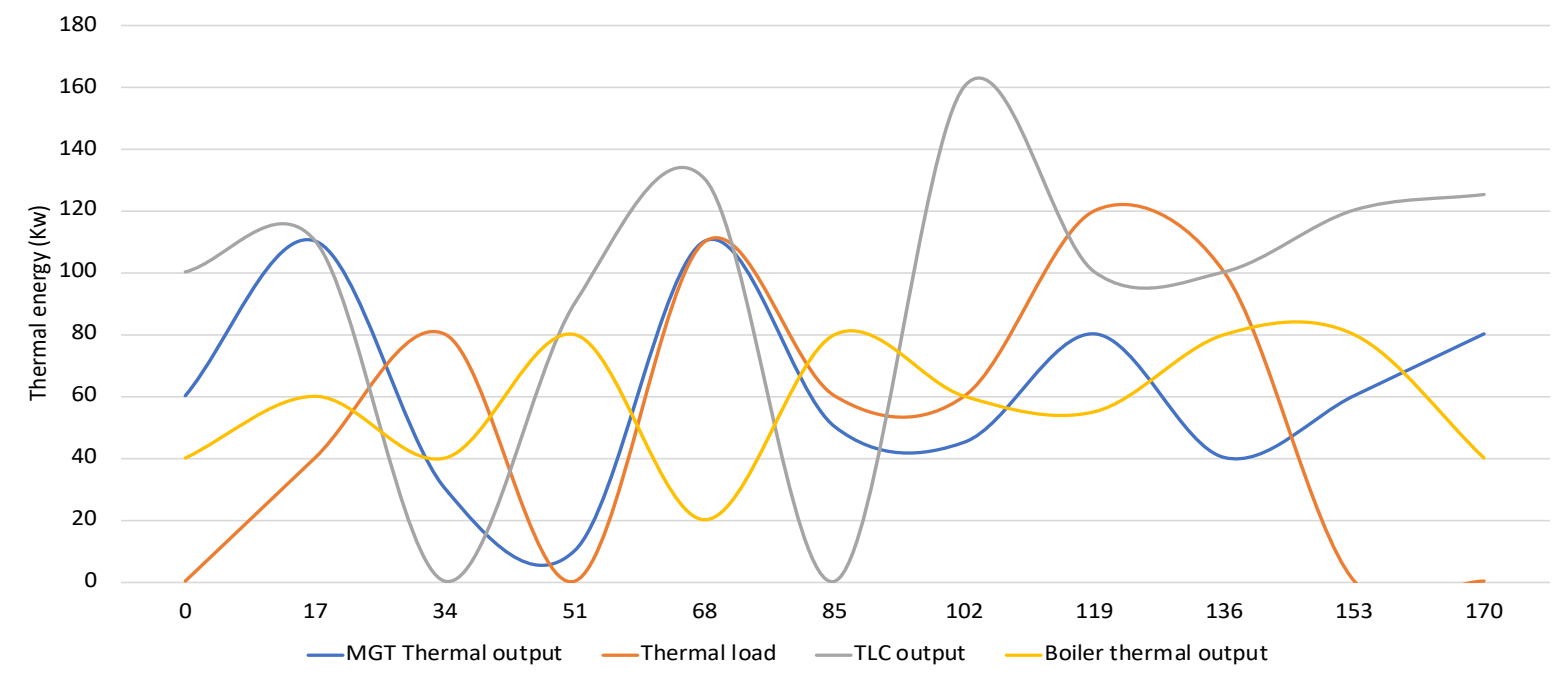

Fig. 4. Time series information of the proposed model

\section{Conclusion}

The MGT based excess recovered waste and electricity are simultaneously used for satisfying the thermal and electrical loads by means of an integrated battery, MGT, wind and PV based system presented in this paper. HOMER platform is used for simulation and analysis of the performance parameters. Various strategies are implemented for meeting the simultaneous 
Journal of Electronics and Informatics (2021)

Vol.03/ No.02

Pages: $89-98$

https://www.irojournals.com/iroei/

DOI: https://doi.org/10.36548/jei.2021.2.002

thermal and electrical as well as only the electric loads while comparing the environmental and techno-economic indicators between them. The thermal and electric loads are met simultaneously or just the electric load is met using the battery, MGT, wind and PV based integrated system in which the NPC and COE are compared. The waste heat recovery unit and excess electricity are used to meet the thermal demand while substantially reducing the size of hardware components inclusive of the inverter, battery, MGT, wind turbine and PV module. For all the analyzed system options, the NPC and lower COE values are obtained by the CC strategy. Under LF option based operation, the electric demand alone is satisfied by the hybrid scheme while generating huge amount of excess energy. The hardware sizing, emission and cost effects are estimated while meeting the thermal and electric load requirements during integration of recovered waste heat and thermal load controller. In case of a CCHP option, the cooling load satisfaction using absorption chillers or electric and thermal storage integration may be performed in future work. Battery and other hardware component degradation factors may be estimated to enhance the optimization cost and accuracy of the system. Various reliability indices and smart techniques may also be implemented for further optimization.

\section{References}

[1] Ramesh, M., \& Saini, R. P. (2020). Dispatch strategies based performance analysis of a hybrid renewable energy system for a remote rural area in India. Journal of Cleaner Production, 259, 120697.

[2] Chauhan, A., \& Saini, R. P. (2017). Size optimization and demand response of a standalone integrated renewable energy system. Energy, 124, 59-73.

[3] Ishraque, M. F., Shezan, S. A., Ali, M. M., \& Rashid, M. M. (2021). Optimization of load dispatch strategies for an islanded microgrid connected with renewable energy sources. Applied Energy, 292, 116879.

[4] Ramesh, M., \& Saini, R. P. (2020). Demand Side Management based techno-economic performance analysis for a stand-alone hybrid renewable energy system of India. Energy Sources, Part A: Recovery, Utilization, and Environmental Effects, 1-29.

[5] Ogunmodede, O., Anderson, K., Cutler, D., \& Newman, A. (2021). Optimizing design and dispatch of a renewable energy system. Applied Energy, 287, 116527. 
Journal of Electronics and Informatics (2021)

Vol.03/ No.02

Pages: $89-98$

https://www.irojournals.com/iroei/

DOI: https://doi.org/10.36548/jei.2021.2.002

[6] Kumar, S., Kaur, T., Upadhyay, S., Sharma, V., \& Vatsal, D. (2020). Optimal Sizing of Stand Alone Hybrid Renewable Energy System with Load Shifting. Energy Sources, Part A: Recovery, Utilization, and Environmental Effects, 1-20.

[7] Li, X., Gui, D., Zhao, Z., Li, X., Wu, X., Hua, Y., ... \& Zhong, H. (2021). Operation optimization of electrical-heating integrated energy system based on concentrating solar power plant hybridized with combined heat and power plant. Journal of Cleaner Production, 289, 125712.

[8] Patel, A. M., \& Singal, S. K. (2019). Optimal component selection of integrated renewable energy system for power generation in stand-alone applications. Energy, 175, 481-504.

[9] Vallem, V. M., \& Kumar, A. (2020). Retracted: Optimal energy dispatch in microgrids with renewable energy sources and demand response. International transactions on electrical energy systems, 30(5), e12328.

[10] Culaba, A. B., Del Rosario, A. J. R., Ubando, A. T., \& Chang, J. S. (2020). Optimal design of an integrated renewable-storage energy system in a mixed-use building. International Journal of Energy Research, 44(12), 9646-9658.

[11] Sifakis, N., Konidakis, S., \& Tsoutsos, T. (2021). Hybrid renewable energy system optimum design and smart dispatch for nearly Zero Energy Ports. Journal of Cleaner Production, 127397.

[12] Das, B. K., Tushar, M. S. H., \& Hassan, R. (2021). Techno-economic optimisation of stand-alone hybrid renewable energy systems for concurrently meeting electric and heating demand. Sustainable Cities and Society, 68, 102763.

[13] Wang, H. Flexibility Management in Renewable Energy Source Operated Power Systems using Decision Support System.

[14] Vijayakumar, T., \& Vinothkanna, M. R. (2020). Efficient Energy Load Distribution Model using Modified Particle Swarm Optimization Algorithm. Journal of Artificial Intelligence, 2(04), 226-231.

[15] Bashar, D. A. (2020). Review on sustainable green Internet of Things and its application. J. Sustain. Wireless Syst, 1(4), 256-264. 